\title{
Comparative Impact Study of Neem (Azadirachta indica A. Juss) Products V/s Chemical Insecticides on Mortality of in Star Larvae of Helicoverpa armigera
}

\author{
Umesh Kumar Dangi, B.L. Meena*, B.S. Meena and Deepa Indoria \\ Krishi Vigyan Kendra, (MPUAT) Chittorgarh, Rajasthan, India \\ *Corresponding author
}

\begin{abstract}
A B S T R A C T

\begin{tabular}{l} 
K e y w o r d s \\
Neem products, \\
Insecticides, \\
Helicoverpa armigera, \\
$3^{\text {rd }}$ instar larvae. \\
\hline Article Info \\
$\begin{array}{l}\text { Accepted: } \\
\text { 07 September } 2017 \\
\text { Available Online: } \\
10 \text { November } 2017\end{array}$ \\
\hline
\end{tabular}

Keywords

Neem products,

Insecticides,

$3^{\text {rd }}$ instar larvae.

Article Info

Accepted:

Available Online:

This study was conducted to evaluate the third instar larvae of Helicoverpa armigera mortality percentile. Different kind of neem products such as leaf extract, neem seed kernel extract and neem oil were used alone and in combination at the concentrations of 5 percentile of each treatment. There was a significant difference in the mortality percentile and all the treatments were effective. The third instar larvae were more susceptible to the neem products and after 72 hours the maximum mortality 39.98 percentile was observed in the treatment where the neem leaf extract + neem oil was used third instar larvae of $H$. armigera at the exposure. In different chemical insecticides (Chlorpyriphos $40 \mathrm{EC}$, Lamda cyclothrin 5EC, Cypermethrin 25 EC, Idoxacarb 14.5 SC) of 200 ppm were against third instar larvae of Helicoverpa armigera mortality percentile. Results showed Indoxacarb14.5 SC insecticide was very effective for third instar larvae at $200 \mathrm{ppm}$ concentration which gave maximum mortality 81.63 percentile after 72 hours. Results reveal that the neem leaf extract + neem oil and Indoxacarb can be used in the integrated pest management programme for all lepidopteron insect affected crops.
\end{abstract}

\section{Introduction}

The pod borer, Helicoverpa armigera is widely distributed in Asia, Africa, Oceania and the Europe. In India, it is distributed throughout the country ranging from the tropical Andaman and Nicobar Islands to temperate Jammu and Kashmir. It is commonly referred as gram pod borer, American bollworm, tomato fruit borer, etc. according to the crop it infests. It has been reported on a wide range of crops in many countries including India. The ability to adopt on the diverse cropping system renders it as a very serious pest. It is a noxious pest. It is the most devastating insect pest inflicting serious damage to the crop. Light trap studies carried out in northern India at Hissar and in
Southern India and at Patancheru revealed that over 90 percent of the total catch of Helicoverpa comprised. Helicoverpa armigera has been recorded feeding on 181 cultivated and uncultivated plant species belonging to 45 families: 40 dicots and 5 monocots. The high damage zone includes Punjab, Hissar, some part of Rajasthan and most part of U.P. and Eastern part of Bihar, Maharashtra, Karnataka, the moderate zone covers in M.P., Gujarat, Tamilnadu and Andhra Pradesh and the low zone encompasses Orissa, Gujarat, West Bengal and some parts of Rajasthan A single larva of gram caterpillar, Helicoverpa armigera can destroy 30 to 40 pods before its maturity. 
Annual damage due to Helicoverpa armigera alone in around 150 to 250 millions \$. Helicoverpa armigera generally known as legume pod borer is one of the most important constraint to crop production globally

To mitigate the losses due to this pest, huge quantities of pesticides are used in many crops. Excessive reliance on chemicals has led to the problem of resistance, resurgence, environmental pollution and decimation of useful fauna and flora. Crops suffer heavy losses from ravages of different insect pest, both during vegetative and fruiting stage.

\section{Materials and Methods}

\section{Preparation of five per cent Neem leaf extract}

Fresh Neem leaves were collected and brought to the laboratory, washed thoroughly 3-4 times with tap water and then chopped into small pieces with a knife. Fifty grams of the chopped leaves were soaked overnight in enough water, squeezed through muslin cloth. The residue was grounded in mortar and pestle, the mixture was then filtered through muslin cloth and volume was made up to one litre and used for pods dip.

\section{Preparation of five per cent Neem Seed Kernel Extract (NSKE)}

Fifty grams of powdered seeds of neem was soaked overnight in one litre of water to prepare five percent neem seed kernel extract, squeezed through muslin cloth and extract collected was used for pods dip.

\section{Preparation of five per cent neem oil}

Neem seeds were dried in sunshine for ten days and the oil was extracted by using the conventional oil extraction method from local market and the extracted oil was allowed to stand undisturbed for two days, then the upper layer of the oil was skimmed and the pure neem oil was $50 \mathrm{ml}$ of taken and the volume was made to one liter by adding water and used for pods dip.

\section{Bioassay}

The trial was conducted at laboratory of Department of Plant Protection, Sam Higginbottom Institute of Agriculture, Technology and Sciences (Deemed-To- BeUniversity), Allahabad (U.P.) India. The bioassay was done in beaker by using pod dip method and for this purpose the solution was diluted to $5 \%$ by adding water in extracts. The chickpea pods were dipped in the extracts of different treatments of neem viz. neem leaf extract (T1), neem oil (T2), neem seed kernel extract (T3) neem leaf extract + neem oil (T4) and control (T0) for 20 seconds and were kept in air 1-2 minutes for drying. The pods were dipped in water in control. In chemical insecticides treatments of Chlorpyriphos 40EC (T1), Lmbda cyclothrin 5EC (T2), Cypermethrin 25EC (T), Indoxacarb 14.5 SC (T4) and control (T0) of solution was diluted to $200 \mathrm{ppm}$ by adding water. The pods were dipped in water in control. There were four replicates of every treatment and in each beaker 25 larvae of third instar of $H$. armigera collected from the field were put in a separate set of beaker on the treated pods and each beaker was covered with the lid so as to avoid the escape of the larvae. The data of the mortality \% was collected after 24, 48 and 72 hours for $3^{\text {rd }}$ instar of $H$. armigera counting the dead and alive larvae and the dead larvae were removed after every count.

\section{Results and Discussion}

The results (Table 1) showed that mean percent mortality of the $3^{\text {rd }}$ instar larvae of the pod borer, Helicoverpa armigera varied significantly among the treatments and 
control. The percent mortality varied among periods, i.e. 24, 48 and 72 hours at all the exposure intervals. The maximum mortality after 24 hours was caused by T4 (Neem leaf extract + neem oil) which was $19.63 \%$, however, low mortality $(6.53 \%)$ was observed in T1 (Neem leaf extract) similarly T2 (Neem oil) and T3 (Neem seed kernel extract) caused $13.95 \%$, and $9.77 \%$ mortality, respectively. After 48 hours exposure interval the lowest mortality (14.23\%) was observed in T1 (Neem leaf extract) and the maximum $(25.20 \%)$ was in T4 (Neem leaf extract + neem oil) against $3^{\text {rd }}$ instar of $H$. armigera and all the treatments were significantly different from each other at $p=0.05 \%$. In the same way, mean mortality of the 3rd instar larvae of $H$. armigera was significantly different from each other and the it was maximum when treated with T4 (Neem leaf extract + neem oil) and it reached up to $39.98 \%$ mortality, however, the lowest value (24.41\%) was observed in T1 (Neem leaf extract) after 72 hours of exposure interval.

The present results are corroborating with the work of Ma et al., (2000 a, b) who stated that when the larvae were exposed to the neem based products for long time the mortality increased.

Table.1 Effect of chemical insecticides on mortality percentage of Helicoverpa armigera third instar larvae after 24 hours, 48 hours and 72 hours of exposure

\begin{tabular}{|c|c|c|c|c|}
\hline \multicolumn{2}{|c|}{ Treatments } & \multicolumn{3}{c|}{ Mean mortality \% of four replicate } \\
\cline { 3 - 5 } & Control & $\mathbf{2 4}$ hrs & $\mathbf{4 8 ~ h r s}$ & $\mathbf{7 2 ~ h r s ~}$ \\
\hline $\mathrm{T}_{0}$ & - & - & - \\
\hline $\mathrm{T}_{1}$ & Chlorpyriphos40EC $(200 \mathrm{ppm})$ & 40.88 & 65.91 & 71.09 \\
\hline $\mathrm{T}_{2}$ & Lmbda cyclothrin 5EC $(200 \mathrm{ppm})$ & 47.28 & 69.27 & 78.80 \\
\hline $\mathrm{T}_{3}$ & Cypermethrin25EC $(200 \mathrm{ppm})$ & 43.01 & 59.29 & 66.55 \\
\hline $\mathrm{T}_{4}$ & Indoxacarb 14.5 SC $(200 \mathrm{ppm})$ & 52.86 & 71.39 & 81.63 \\
\hline \multicolumn{2}{|c|}{ F- test } & $\mathrm{S}$ & $\mathrm{S}$ & $\mathrm{S}$ \\
\hline \multicolumn{2}{|c|}{ S. Ed. $( \pm)$} & 0.764 & 0.655 & 0.616 \\
\hline \multicolumn{2}{|c|}{ C. D. $(\mathbf{P}=\mathbf{0 . 0 5})$} & 1.619 & 1.389 & 1.305 \\
\hline
\end{tabular}

In chemical insecticides the maximum mortality after 24 hours was caused by T4 (Indoxacarb 14.5 SC 200ppm) which was $52.86 \%$, however, low mortality $(43.01 \%)$ was observed in $\mathrm{T} 3$ (Cypermethrin 25 EC 200ppm) similarly T1 (Chlorpyriphos 40 EC 200ppm) and T2 (Lmbda cyclothrin 5 EC 200ppm) caused $47.28 \%$, and $43.01 \%$ mortality, respectively. After 48 hours exposure interval the lowest mortality (59.29\%) was observed in T3 (Cypermethrin 25 EC 200ppm) and the maximum (71.39\%) was in T4 (Indoxacarb 14.5 SC 200ppm) against $3^{\text {rd }}$ instar of $H$. armigera and all the treatments were significantly different from each other at $p=$ $0.05 \%$. In the same way, mean mortality of the 3rd instar larvae of $H$. armigera was significantly different from each other and the it was maximum when treated with $\mathrm{T} 4$ (Indoxacarb 14.5 SC 200ppm) and it reached up to $81.63 \%$ mortality, however, the lowest value (66.55\%) was observed in T3 (Cypermethrin 25 EC 200ppm) after 72 hours of exposure.

The results of the present study showed that $\mathrm{T}_{4}$ $=$ Neem leaf extract + Neem oil $5 \%$ was more effective as compared to treatment $\mathrm{T}_{0}=$ Control for third instar larvae of Helicoverpa armigera..The same results were observed by Wakil et al., (2008) The 2nd instar larvae were more susceptible to the neem products and after 72 hours the maximum mortality was observed in the treatment where the neem leaf extract + neem oil was used. This treatment gave the mortality of 4th instar larvae of $H$. armigera at 
the same exposure interval. The results of the present study showed that Indoxacarb 14.5 SC (200ppm) was more effective as compared to treatment $\mathrm{T}_{0}=$ Control for third instar larvae of Helicoverpa armigera. The same results were observed by Ahmed et al., (2007) that Indoxacarb 150SC (200ppm) was most effective against to second, third, four instar larvae of Helicoverpa armigera. The same results were observed by Johson et al., (2000) form the study of differently insecticide had been evaluated against $H$. armigera found Indoxacarb was more effective.

\section{References}

Ahmad, M., (2007). Insecticide resistance mechanisms and their management in Helicoverpa armigera (Hübner). A Review: J. Agric. Res., 45(4): 319-335.

Ali, Masood. (1998). Research Development and management for production in India. Vol.4 Pulses (eds.), K.U. Rajeev, K.G. Mukherjee and R.L. Rajak. Adithya Book Private Limited pp.509.

Bajya, D. R., Monga, D., Tyagi, M. P. and Meena, B. L. (2010). Population dynamics of Helicoverpa armigera on chick pea, Pigeon pea and Cotton in Correlation with weather parameters. Ann. Pl. Protect. Sci. 18(1): 223-282.

Ma, D., G. Gordh and M. P. Zalucki (2000a). Survival and development of Helicoverpa armigera (Hübner) (Lepidoptera: Noctuidae) on neem (Azadirachta indica A. Juss) leaves. Austr. J. Entomol., 39: 208-211.

Ma, D., G. Gordh and M.P. Zalucki (2000b).
Biological effects of Azadirachtin on Helicoverpa armigera (Hübner) (Lepidoptera: Noctuidae) fed on cotton and artificial diet. Austr. J. Entomol., 39: 301-304.

Reed, W. And Pawer, C. S. (1982). Heliothis: A global problem. In: proc. Int. Workshop Halitosis management. ICRISAT, patancheru, India. Pp: 9.

Sachan, J. N, (1992). A.I.C. Pulses improvement project. Rabi pulses workshop, Consolidated Report on Rabi pulses. 1992-1993.

Singh,R. and Ali, S. (2005). Efficacy of biopesticides in the management Helicoverpa armigera (Hubner) in chickpea. Ann. Pl. protec. Sci. 13: 94-96.

Sithanantham, S., Rao, V. and Ghalar, M. A. (1984). International review of crop losses caused by insects on chickpea. In: Proceedings of National Seminar in Crop losses due to Insect Pests, 7-9January, 1983 APA; 269-284 pp, Hyderabad, A.P., India.

Wakil, W., Ashfaq, M., Ghazanfar, M.U., Akhtar, S. and Malhi, Z. A. (2008). Laboratory bioassay with neem (Azadirachta indica a. Juss) products to Control Helicoverpa armigera (hübner) fed on chickpea Pak. Entomol., 30(1): 5154.

Zalucki, M. P., Daglish, F. S. And Twine, P. R. M. (1986). The biology and ecology of Heliothis armigera and $H$. punctigera Wallengren in Australia: what do we know? Australian Journal of Zoology $34: 779-814$.

\section{How to cite this article:}

Umesh Kumar Dangi, B. L. Meena, B. S. Meena and Deepa Indoria. 2017. Comparative Impact Study of Neem (Azadirachta indica A. Juss) Products V/s Chemical Insecticides on Mortality of in Star Larvae of Helicoverpa armigera. Int.J.Curr.Microbiol.App.Sci. 6(11): 465-468. doi: https://doi.org/10.20546/ijcmas.2017.611.055 